of the functions of science is to quantify. Among the many other reasons are simply concern about the environment. If someone says, "We will rip out this relic ecosystem because we can build you another one," we need to be able to hand them a document that quantifies the standards they must meet in hope that they will realize the cost, difficulty, and long-term commitment of restoration. They may then prefer to change their plans and leave the relic system undisturbed. In any case, as we discuss restoration, management, and environmental quality generally, there is a real need to quantify at least the species diversity, genetic makeup, and dynamics of the systems we are talking about.

Aldo Leopold stated in A Sand County Almanac, "In our attempt to make conservation easy, we have made it trivial." If we quantify ecosystem restoration, it will be clear that it is not easy and thus not trivial. It will also communicate the complexity of all ecosystems.

Have you begun to develop quantitative standards for the ecosystem restorations that you are working with? If you have, will you share your results and your views?

Karl D. Smith Senior Naturalist, Brecksville Nature Center, Cleveland Metroparks System, 9305 Brecksville Rd., Brecksville, OH 44147 (216) 526-1012

\section{Researcher Argues Craft Needs Firmer Foundations}

The applied biological sciences have in common a similar framework for addressing the problems with which they are concerned. One integral aspect of this framework is that it is goal directed-that is, there is some particular state desired for the biological system under consideration. The science is concerned with the development of techniques for manipulating biological processes in such a way that the system is shifted toward the desired state. Scientific assessment of the capabilities of different techniques to shift systems toward desired states is conducted through evaluation programs in which systems are monitored to determine the effectiveness of prescribed techniques. Obviously, a close relationship between theory and practice is involved, since practical efforts based on fundamental ideas often provide critical tests of the basic paradigms upon which the practical efforts are based.

Restoration and management of ecological communities or habitats clearly is one of these applied biological sciences. Two characteristics of restoration and management become apparent upon examining the literature relevant to this field. First, though efforts in this area are invariably goal oriented, there is no generally accepted goal (or sets of standards) that guides practical restoration and management. For example, the goal of assembling a system that will persist on bare soil or in a newly created body of water differs greatly from the goal of creating replicas of presettlement habitats from degraded systems already present on a site. The diffuse nature of goals in restoration and management contrasts with those that have been developed in other applied disciplines such as agriculture or medicine. These applied sciences have rather well-defined sets of goals and hence are more focused as applied sciences than restoration and management.

A second generalization that emerges from a survey of the literature of restoration and management is that theory pertaining to how ecological processes affect the condition of systems present on a site and to the establishment of goals for restoration and management have repeatedly been found to have little value for guiding management of real biological systems. Instead of ecological theory providing a framework for successful restoration and management, it is the inability of this theory to guide restoration and management that has, in effect, revealed that the emperor has no clothes.

Similar failures of theory, revealed by work in other applied sciences, have resulted in the reformulation of the basic science upon which the applied science is based. Presumably this can happen in our field as well, and it seems to me the results would be extremely beneficial.

In the absence of a useful set of guiding principles, practical decisions tend to be made "by the seat of the pants," with the personal biases and experiences of decision-makers strongly influencing the course of action taken. Frequently, "Let's get something done," or "Go ahead and try it" becomes the sole rationale underlying the decision-making process. The result is a plethora of independently derived techniques, each reflecting a different set of assumptions about the processes influencing the current state of a given habitat, as well as the unorganized body of information that currently characterizes the field. It is true that the uniqueness of local conditions, as well as potential confounding effects of uncontrolled (and uncontrollable) variables, make this a complex field in which it is difficult to construct useful generalizations. In the absence of such generalizations, however, the effectiveness of management is likely to depend upon the intuition, insight, and accumulated experience (in other words, the craftsmanship) of the person or persons making decisions about the course of action on a site. The problem is that all too often the background and training of the people involved are inadequate, and the result is ineffective management or even mismanagement. Lastly, there almost never is a built-in procedure for evaluating the results of management programs; this essential component of any goal-directed activity is almost always dispensed with as being too costly.

What is needed is a way of providing training and discipline such that managers can make enlightened decisions-that is, decisions with a high probability of achieving well-defined restoration and management goals. This training in the science of ecological restoration and management clearly has to have some sort of foundation in the biological sciences. The spectacular 
successes of agriculture and medicine, for example, can be traced directly to the roots of these disciplines in basic genetics and physiology. An emergent science of restoration and management will be based on genetics and ecology, but will be committed to the development of techniques for manipulating communities and habitats to achieve specified goals.

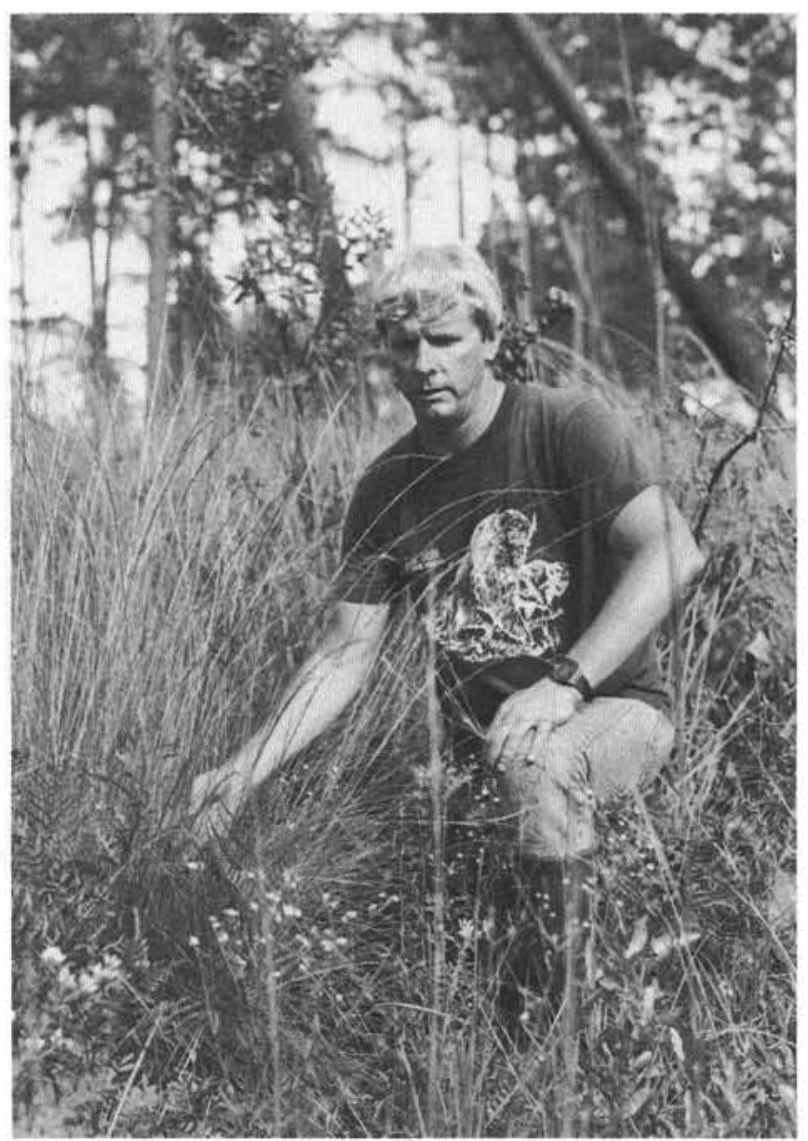

William J. Platt

To me, there are two considerations that must be taken into account in developing a logical framework for ecological restoration and management. First, techniques for inducing change are likely to involve environmental alterations that affect whole assemblages of species. Only rarely will we be able to influence one species without at the same time affecting other species also present in a community. This will especially be the case for techniques such as prescribed burning or manipulation of water levels which alter the entire environment. Second, it must be kept in mind that the fundamental units that respond to induced changes are populations. Populations have many different characteristics-density, birth and death rates, rates of increase or decrease, age/size classes, spatial dispersion and locations of individuals, genetic compositions, and so on-that are likely to determine their responses to a particular manipulation. Deter- mining the effects of manipulations upon populations of the large numbers of species present in even one habitat is likely to be staggeringly difficult.

Nonetheless, the ability of a technique to bring about predictable changes in populations is a critical test of its usefulness. For this reason, the basis for the discipline of ecological restoration and management must be sought in population genetics and population ecology. Unfortunately, these two fields are far apart in their approaches to populations, and each has developed extensive theory that is likely to have little direct relevance to actual restoration and management. The challenge, therefore, will be to develop concepts in these two fields that can guide restoration and management effectively. Doing this will undoubtedly benefit practical restoration and management and will also provide valuable to the development of theory in these basic sciences.

William J. Platt

Research Biologist, Tall Timbers Research Station, Route 1, Box 678, Tallahassee, FL 32312 (904) 893-4153; and Associate Professor of Biology, Florida State University. 